\section{The "battle" against cancer}

Downar is to be praised for his brave call to abandon the outmoded language of warfare in the "battle" against cancer. ${ }^{1}$ Our job is to help people with cancer survive their illness as well as possible for as long as possible. We do them a terrible disservice by suggesting that their individual strength of character and ability to endure suffering will pull them through. To do so ignores all the evidence about both low and high mortality rates for various cancers despite maximal therapy and patient commitment to be cured. So much of the influence on survival either predates diagnosis or depends on early diagnosis and treatment for so many cancers. We must avoid the risk of adding insult to injury by mindlessly blaming the patient for lack of response to treatment. As a lucky survivor of colon cancer, I credit the expertise of my physician and surgeon for my survival rather than my own "inner strength."

\section{Paul J. Byrne MD}

Stollery Children's Hospital, Edmonton, Alta.

\section{Reference}

1. Downar J. Cancer: it's time to change the sign CMAJ 2010;182:1588.

DOI: $10.1503 / \mathrm{cmaj} .110-2128$

\section{Steroids in infection: an old wives' tale}

In their otherwise informative vignette about a 48-year-old woman presenting with headache, red eyes, blurred vision and hearing loss, Chan and colleagues perpetuate a common medical myth. They caution that, "systemic steroids should not be administered before an underlying infection, which could be the cause of this clinical presentation, has been excluded."
Unfortunately, there is a dearth of evidence supporting this claim, and at least one good study, which reaches the opposite conclusion. McGee and Hirschmann reviewed published randomized double-blind trials of steroids in infection and concluded that steroids are beneficial and safe for a wide variety of infections. ${ }^{2}$ They noted that, for bacterial meningitis, steroids likely improve outcomes. Steroids were associated with worse outcomes for only two types of infections: viral hepatitis and cerebral malaria.

Dogged adherence to the old wives' tale about steroids and infection continues to create the potential to delay safe and effective treatment.

\section{Vinay Prasad MD}

Department of Medicine, Northwestern University, Chicago, USA

\section{References}

1. Chan EW, Sanjay S, Chang BC. Headache, red eyes, blurred vision and hearing loss. CMAJ 2010; 182:1205-9.

2. McGee S, Hirschmann J. Use of corticosteroids in treating infectious diseases. Arch Intern Med 2008; 168:1034-46.

DOI: $10.1503 /$ cmaj.111-2003

We thank Prasad for his comments and agree that there is some evidence for clinical benefit of steroids in terms of survival, functional deficit and symptoms. ${ }^{1}$ Our comment that steroids should be withheld before excluding an underlying infection in patients with meningitis may be misleading in suggesting that steroids are not useful for bacterial and tuberculous meningitis, because there is some evidence of benefit in these conditions. ${ }^{1}$ The evidence needs to be reexamined. We also need to individualize treatment.

The conclusion by McGee and Hirschmann that steroids are beneficial and safe for a wide variety of infections ${ }^{1}$ should not be taken at face value. There are infections (e.g., bacterial meningitis, severe typhoid fever and tetanus) for which the clinical benefit of steroid treatment has not been convincingly shown for all patients. Although some investigators have seen improved outcomes for bacterial meningitis, ${ }^{2,3}$ others have found no benefit. ${ }^{4,5}$ Furthermore, the observed clinical benefit of steroids for typhoid fever and tetanus was found in studies that involved only patients with more severe disease. ${ }^{6,7}$

The application of evidence-based recommendations on treatment should be appropriate to the specific clinical context. The studies of bacterial meningitis included only patients who had supporting evidence of bacterial infection (i.e., cloudy cerebrospinal fluid, bacteria seen on gram stain or white blood cell count $\left.>1000 \times 10^{9} / \mathrm{L}\right){ }^{4,6}$ Our patient was a 48 -year-old woman with meningitis of unknown cause, and clinical assessment of cerebrospinal fluid suggested that the cause was nonbacterial. Furthermore, a risk-benefit analysis suggests that witholding treatment is preferred so as not to aggravate unidentified infections (e.g., fungal) with steroid treatment.

We subsequently diagnosed VogtKoyanagi-Harada disease. Retrospectively, we find little justification for empirical steroid treatment, given that this disease is not known to cause death or neurologic disability.

\section{Errol W. Chan MBBS}

S. Sanjay MS(Ophth)

\section{Benjamin C. Chang MB BCh}

Department of Ophthalmology and Visual Sciences, Alexandra Hospital, Singapore

\section{References}

1. McGee S, Hirschmann J. Use of corticosteroids in treating infectious diseases. Arch Intern Med 2008; 168:1034-46.

2. de Gans J, van de Beek D; European Dexamethasone in Adulthood Bacterial Meningitis Study Investigators. Dexamethasone in adults with bacterial meningitis. N Engl J Med 2002;347:1549-56.

3. Lebel MH, Freij BJ, Syrogiannopoulos GA, et al. Dexamethasone therapy for bacterial meningitis. Results of two double-blind, placebo-controlled trials. N Engl J Med 1988;319:964-71.

4. van de Beek D, Farrar JJ, de Gans J, et al. Adjunctive dexamethasone in bacterial meningitis: a meta- 